\title{
An overview of abuse-deterrent opioids and recommendations for practical patient care
}

This article was published in the following Dove Press journal: Journal of Multidisciplinary Healthcare

\author{
Jeremy A Adler' \\ Theresa Mallick-Searle ${ }^{2}$ \\ 'Pacific Pain Medicine Consultants, \\ Encinitas, CA, USA; ${ }^{2}$ Division of Pain \\ Medicine, Stanford Outpatient Medical \\ Center, Redwood City, CA, USA
}

Correspondence: Jeremy A Adler Pacific Pain Medicine Consultants, 477 N. El Camino Real B30I, Encinitas, CA 92024, USA

Tel +I 760753 II04

Email jadler@pacificpainmed.com

\begin{abstract}
Despite advances in the treatment of severe intractable pain, opioids remain a critical and appropriate component of treatment. However, abuse, misuse, and diversion of prescription opioids are significant public health concerns. Opioid abuse-deterrent formulations (ADFs) are one component of an opioid risk management plan to manage patient's pain relief and quality of life while offering some protection against potentially harmful consequences of opioids from misuse and abuse. Opioid ADFs are designed to make manipulation more difficult and administration via non-oral routes less appealing. There are currently nine extended-release and one immediate-release opioid pain medications with US Food and Drug Administration-approved ADF labeling. All use physical/chemical barriers or agonist/antagonist combinations to deter manipulation and abuse. Evidence suggests that opioid ADFs decrease rates of abuse and diversion of opioids in the USA; however, some opioid ADFs are not yet commercially available or have not been on the market long enough to undergo post-marketing data analyses. Opioid ADFs along with the use of prescription drug monitoring programs, clinical assessment tools, toxicology testing, and co-prescribing of naloxone are all tools that can be used to reduce opioid abuse. Patient education on the risks of abuse and diversion is vital and includes a discussion of appropriate use of medication and proper storage. Physician assistants and nurse practitioners are on the "front lines" in battling opioid abuse and serve a key role in recognizing and mitigating the risks of prescription opioid diversion, abuse, and misuse (intentional and unintentional) and in identifying patients at risk for abuse while still providing pain relief to patients.
\end{abstract}

Keywords: abuse, abuse-deterrent, diversion, misuse, opioid

\section{Hypothetical case study}

Elizabeth is a 68-year-old woman experiencing severe pain as she recovers from back surgery for a herniated disc. Before surgery, her severe pain was manageable with an extended-release (ER) opioid, but her pain has escalated postoperatively, as expected. She has a history of hypertension and chronic low back pain, but no history of smoking, alcohol use, or substance abuse. She complains of sometimes finding it difficult to swallow. She is a widow living alone. She has two daughters who visit often, a handyman who assists with various home maintenance projects as needed, and a housekeeping service that visits weekly. A personal-care attendant is visiting daily for several hours to assist Elizabeth's daughters in providing care during their mother's post-operative recovery period.

Results from the Opioid Risk Tool (ORT; a specific, validated questionnaire that screens for risk stratification) indicate that Elizabeth is at a low risk for opioid abuse. 
Her additional acute on chronic severe pain is expected to continue for at least 2 weeks post-operatively, so she is prescribed a 2-week supply of immediate-release (IR) opioid. The prescriber counsels the patient regarding side effects, safety risks, and risks of dependence and addiction with long-term opioid use; however, the prescriber does not discuss the need to keep medications secure at home or that the medications should be disposed of properly when no longer a part of her treatment plan.

\section{Concerns}

The patient calls the clinic for a refill of the IR opioid medication after just 1 week, stating that she has run out of pills and is almost out 5 days earlier than expected for her ER opioid. She reports that she does not believe that she took more than was prescribed, but she cannot explain why her supply is gone so early. When asked, she states that she has been storing the prescription bottle on her nightstand because her post-operative pain has kept her in bed most of the day.

\section{Considerations}

- Possible patient misuse of opioid medication:

- Determine total daily dose currently being used.

- Make sure patient understands appropriate use and dosing frequency.

- Counsel patient again on safety risks.

- Consider prescribing an opioid abuse-deterrent formulation (ADF) in case the patient is manipulating the pills due to her difficulty in swallowing.
- Possible unintentional diversion:

- Consider reiterating the importance of locking up the medication rather than leaving it on a nightstand and the danger exposed opioid medication poses to unintended users.

- Consider prescribing an opioid ADF to minimize risk if pills are diverted and to reduce the desirability of an abuser to divert the pills.

- Consider providing a handout or brochure to remind the patient of the safety risks associated with opioid medications and methods to reduce the potential for diversion.

- Also consider reducing the prescription's duration, dependent on patient's pain control.

- Consider exploring other non-pharmacologic pain management strategies.

\section{Public health implications of opioid misuse and abuse}

Despite advances in the treatment of severe intractable pain, opioids remain a critical and appropriate component of treatment. However, since 1999, there have been increases in prescription opioid-related overdose deaths and admissions for treatment of opioid use disorder (Figure 1). ${ }^{1-3}$ There were 66,972 deaths attributed to drug overdoses in the 12-month period ending July 2017 in the USA, 58.3\% of which involved an opioid (excluding heroin or methadone). ${ }^{4}$ This reflects a marked increase from the previous year both in the overall number of deaths attributed to drug overdose $(58,525)$ and in the proportion associated with an opioid (48.0\%). Although

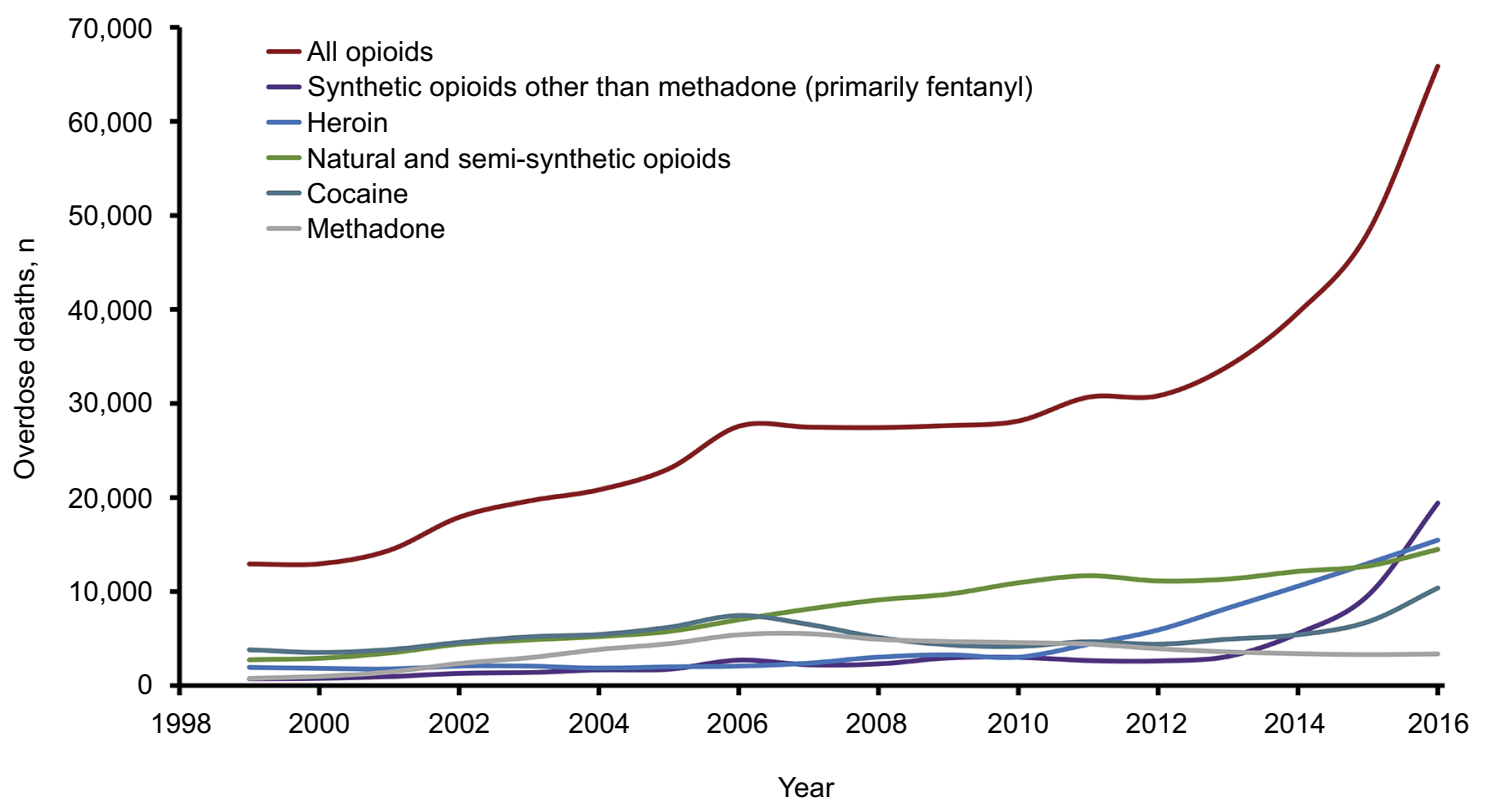

Figure I Drug overdose deaths involving opioids from 1999 to 2016.

Note: Centers for Disease Control and Prevention, National Center for Health Statistics. Multiple Cause of Death 1999-2016 on CDC WONDER Online Database, released December, 2017. Data are from the Multiple Cause of Death Files, 1999-2016, as compiled from data provided by the 57 vital statistics jurisdictions through the Vital Statistics Cooperative Program. Accessed at https://wonder.cdc.gov/controller/saved/D77/D38FI88. ${ }^{3}$ 
this increase is largely driven by the increasing use of illicit fentanyl, abuse (defined as the intentional, nontherapeutic use of a prescription opioid analgesic for the purpose of achieving a desirable psychological or physiological effect ${ }^{5}$ ) and misuse (defined as the use of a prescription opioid analgesic in any way not directed by a doctor, including use without a prescription of one's own and increased amounts/ frequency than prescribed ${ }^{6}$ ) of prescription opioids remain high. ${ }^{4}$ Results from the 2016 National Survey on Drug Use and Health (NSDUH) reveal that in 2016, 11.8 million people aged 12 years or older abused or misused opioids in the past year (including 11.5 million misusing prescription pain relievers), of whom 1.8 million had an opioid-related substance-use disorder related to a prescription opioid. ${ }^{6}$ The economic burden of overdose, abuse, and dependence on prescription opioids in the USA is estimated to be $\$ 78.5$ billion annually. ${ }^{7}$ Over one-third of this amount is attributed to increased health care cost and substance-abuse treatment cost, and one-quarter of the cost is borne by the public sector.?

This increase in the prevalence of misuse of prescription opioids may be because many individuals abuse or misuse opioids they obtain through diversion (any intentional act that results in transferring a prescription opioid analgesic from lawful to unlawful distribution or possession ${ }^{5}$ ) rather than by legitimate prescriptions. In the 2016 NSDUH survey, more than half (53\%) of individuals aged 12 years or older who abused or misused prescription opioids in the past year reported that they obtained the pain relievers the last time from a friend or relative (Figure 2). ${ }^{6}$ Although still constituting misuse, $62 \%$ of those who abused or misused prescription opioids in the past year indicated that their intent was to relieve physical pain. ${ }^{6}$ In a study of state residents who died of unintentional pharmaceutical overdoses in West Virginia in $2006(n=295)$, pharmaceutical diversion was associated with $63 \%$ of deaths and was greatest $(91 \%)$ among 18 - to 24 -year-olds. ${ }^{8}$ These data highlight the importance of considering not only the patient's risk for prescription opioid misuse or abuse but also the risk for diversion (unintentional as well as intentional) when determining the most appropriate management of moderate-to-severe pain. Because not all diversion is intentional, any individual possessing opioids is inherently at risk of diversion. Such consideration is typically lacking in guidelines and policies for safe opioid prescribing. ${ }^{9,10}$ Considering that abused or misused opioids may be obtained through diversion, typical risk assessments, monitoring (eg, toxicology testing), and use of prescription drug monitoring program (PDMP) data of patients may not identify those at the greatest risk.

Opioid misuse, abuse, and diversion are complex problems requiring a multifaceted approach involving all stakeholders, including health care professionals, patients, government agencies, pharmaceutical companies, health care payers, and law enforcement. ${ }^{11}$ In a 2008 Senate Health Committee meeting, the Centers for Disease Control and Prevention recommended that "drug manufacturers should

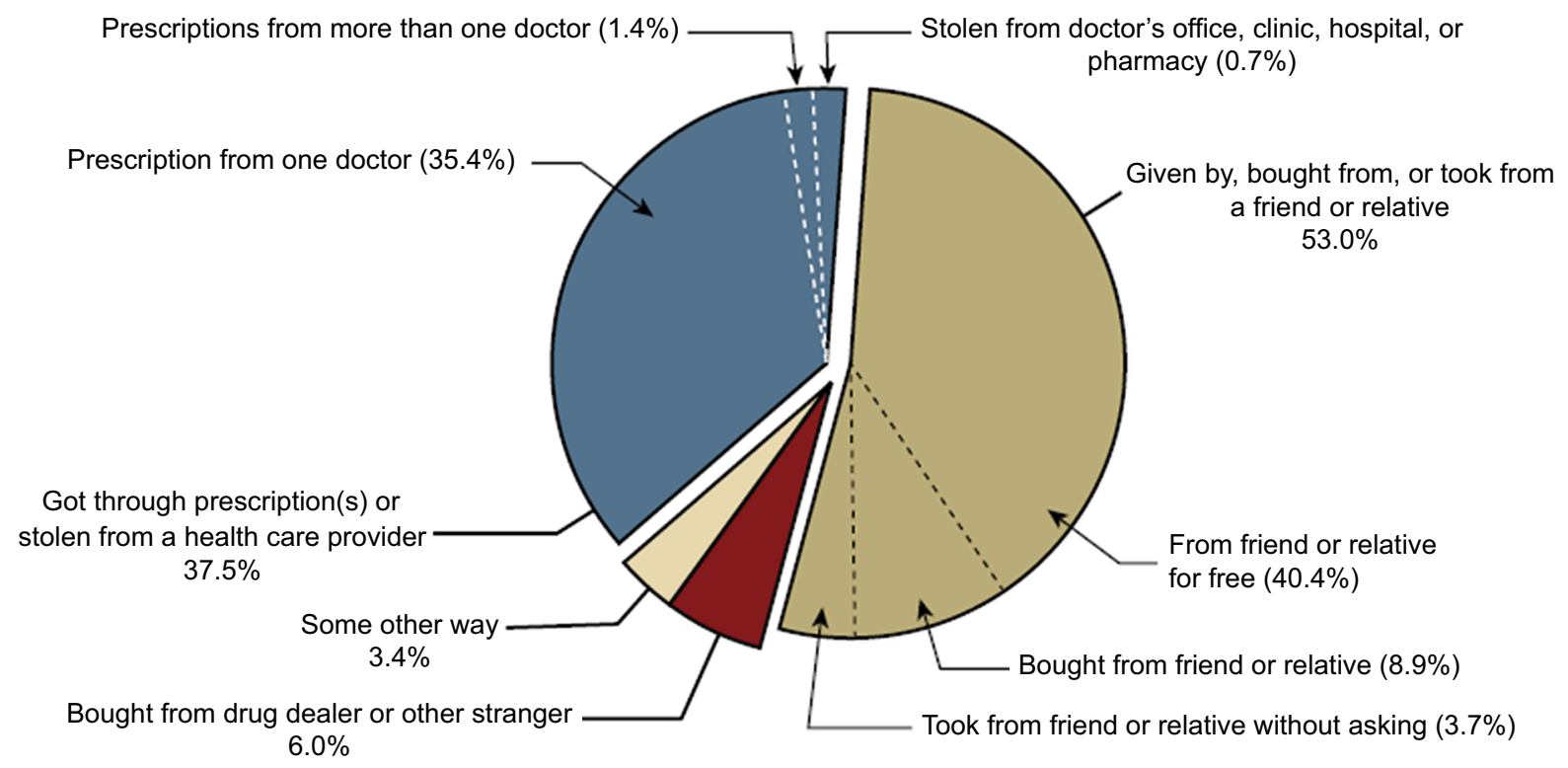

11.5 million people aged 12 or older who misused prescription pain relievers in the past year

Figure 2 Source where pain relievers were obtained for most recent misuse among people aged 12 years or older who misused prescription pain relievers in the past year. Respondents with unknown data for Source for Most Recent Misuse or who reported Some Other Way but did not specify a valid way were excluded. The percentages do not add to 100 percent due to rounding.

Note: Data from Key substance use and mental health indicators in the United States: Results from the 2016 National Survey on Drug Use and Health (HHS Publication No. SMA 17-5044, NSDUH Series H-52). Rockville, MD. 2017. Available from: https://store.samhsa.gov/shin/content//SMAI7-5044/SMAI7-5044.pdf. ${ }^{6}$ 
modify opioid painkillers so that they are more difficult to tamper with and/or combine them with agents that block the effect of the opioid if it is dissolved and injected". ${ }^{12}$ The use of opioid ADFs is one part of the solution to this public health issue. ADFs are designed to be therapeutically equivalent to the original formulation in terms of dose, clinical efficacy, and safety, while reducing the desirability of the opioid by those who seek them for abuse, consequently decreasing the likelihood of diversion of such formulations.

\section{Abuse-deterrent formulations Routes of abuse of prescription opioids}

The most common route of abuse or misuse of prescription opioids is ingestion of a larger dose of intact tablets/capsules than prescribed. However, abusers often attempt to manipulate opioids to overcome ER mechanisms or to permit alternative routes of administration with a faster onset of action (eg, non-oral routes that include intravenous [IV] or intranasal [snorting] administration). The objective of manipulating an ER opioid is to create a "dose-dumping" effect, which is delivery of a more rapid maximum concentration of opioid in the brain to achieve enhanced psychoactive effects. ${ }^{13,14}$ Therefore, manipulations and routes of administration that facilitate dose dumping are associated with greater abuse potential. ${ }^{15,16}$ This is particularly important because abusers may start with the oral route of abuse and then transition to non-oral routes as duration of abuse increases; in addition to concerns about overdose and death, individuals who use non-oral routes of administration are at increased risk for contracting blood-borne infections such as HIV and hepatitis $\mathrm{C}$ or for developing nasal perforation and/or necrosis. ${ }^{15-17}$

\section{ADF strategies}

The development of opioid ADFs is considered a high public health priority by the US Food and Drug Administration (FDA). Because opioid products are often manipulated for non-oral abuse or to defeat ER properties, most abusedeterrent technologies developed to date are intended to make manipulation more difficult or to make abuse of the manipulated product less appealing for non-oral abuse. ${ }^{18}$ The FDA has published specific guidance regarding the requirements needed for studies to demonstrate abuse-deterrent properties for a unique opioid formulation. ${ }^{18}$ Once an opioid formulation is approved with ADF properties, additional post-marketing studies are also required to demonstrate a meaningful reduction in abuse, misuse, and related clinical outcomes, including addiction, overdose, and death.

\section{Types of ADFs}

A variety of approaches have been used to develop opioid ADFs, which include adding physical and chemical barriers and producing agonists/antagonist combinations. Other innovative approaches in development include aversion properties, unique delivery systems, and prodrugs. Figure 3 and the following text summarize these approaches and the FDA-approved ADFs that fit into these categories, organized

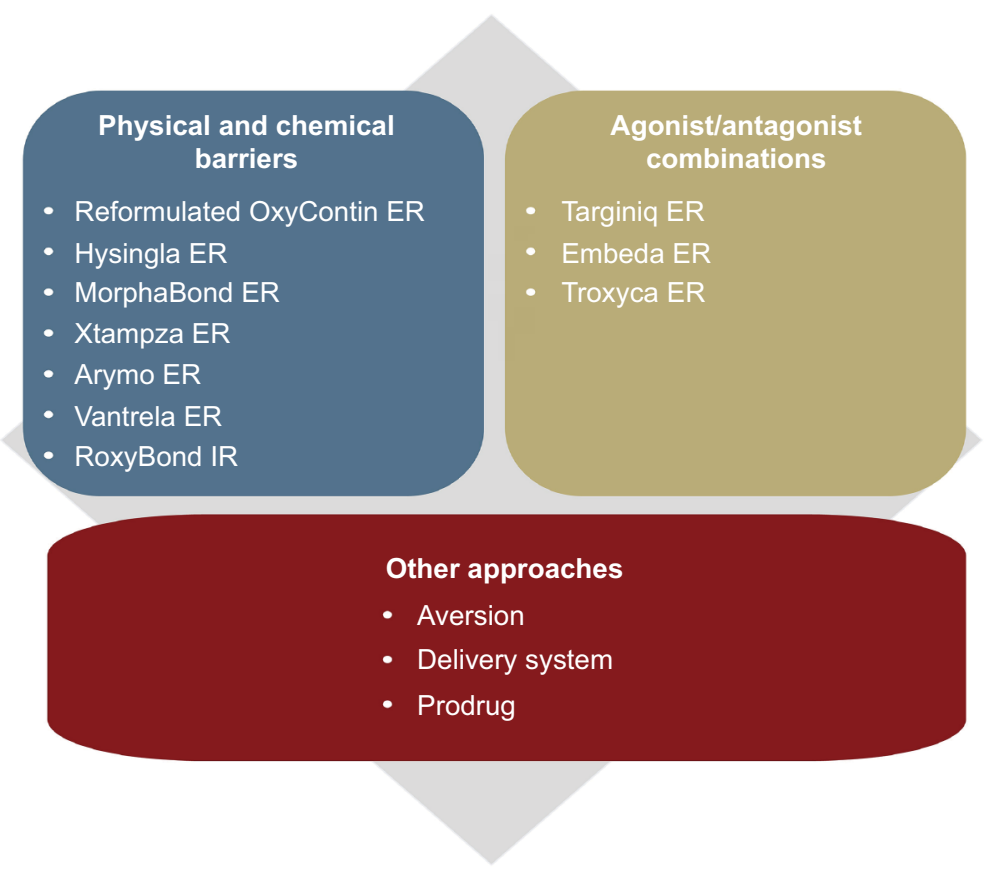

Figure 3 Strategies for developing abuse-deterrent formulations of opioids. Abbreviation: ER, extended-release. 
by commercial availability and approval date. Because opioid ADFs are designed to be bioequivalent to their non-ADF counterparts, doses can generally be easily converted from a non-ADF to the ADF formulation.

\section{Physical and chemical barriers (currently marketed)}

Reformulated OxyContin ${ }^{\circledR}$ (oxycodone ER; Purdue Pharma L.P., Stamford, CT, USA) ${ }^{19}$ was the first FDA-approved abuse-deterrent opioid formulation (approved in 2010). This formulation uses physical and chemical properties that make it difficult to crush the tablet (the originally marketed controlled-release formulation of oxycodone was easily crushed). ${ }^{20}$ The ADF is also resistant to ethanol and other chemical-extraction techniques to enhance dose dumping. ${ }^{20}$ Several trials ${ }^{21-23}$ demonstrate that OxyContin has physicochemical properties expected to make abuse via injection difficult, and these properties are also expected to reduce abuse via the intranasal route.

Hysingla ${ }^{\circledR}$ ER (hydrocodone bitartrate ER; Purdue Pharma), approved in 2014, is formulated with physical and chemical properties that render it difficult to crush, break, or dissolve. ${ }^{24}$ Studies have demonstrated that intact, chewed, ${ }^{25}$ and intranasally ${ }^{26}$ administered Hysingla ER was less liked than either orally administered hydrocodone solution ${ }^{25}$ or intranasally administered hydrocodone powder. ${ }^{26}$ Hysingla ER has physical and chemical properties that are expected to deter intranasal and IV abuse and oral abuse when chewed.

MorphaBond $^{\mathrm{TM}}$ ER (morphine sulfate ER; Daiichi Sankyo, Inc., Basking Ridge, NJ, USA), approved in 2015, uses SentryBond ${ }^{\mathrm{TM}}$ technology that has both physical and chemical properties to deter misuse and abuse by intranasal and IV routes of administration. ${ }^{27}$ In addition, the active ingredient, contained within a polymer matrix of inactive ingredients, is difficult to visibly distinguish or physically separate from the polymer matrix. Compared with non-ADF morphine ER, MorphaBond ER has increased resistance to cutting, crushing, or breaking using a variety of tools. When subjected to a liquid environment, the manipulated formulation forms a viscous material that resists passage through a hypodermic needle. ${ }^{27}$ MorphaBond ER demonstrated significant reductions in drug liking and desire to take the drug again scores compared with crushed intranasal non-ADF morphine ER ${ }^{28}$ and is expected to reduce abuse or misuse via injection or insufflation. MorphaBond ER additionally retains its ER properties, even if manipulated.

$X_{\text {Xtampza }}{ }^{\circledR}$ ER (oxycodone ER; Collegium Pharmaceutical, Inc., Canton, MA, USA), approved in 2016, is a microsphere-in-capsule formulation using proprietary DETERx ${ }^{\circledR}$ technology that is less susceptible to the effects of grinding, crushing, and extraction using a variety of tools and solvents relative to IR oxycodone tablets. ${ }^{20,29}$ Thus, abusers may find this formulation to be less appealing for abuse by injection or intranasal administration. In addition, oral administration of chewed or intact Xtampza ER was liked less than crushed IR oxycodone administered orally. ${ }^{30,31}$ Xtampza ER capsules can be opened and the contents can be sprinkled onto soft foods for oral administration in patients who have difficulty swallowing. Xtampza ER also retains its ER properties, irrespective of manipulation.

Arymo $^{\circledR}$ ER (morphine sulfate ER; Egalet Corporation, Wayne, PA, USA), approved in 2017, is manufactured with Guardian ${ }^{\circledR}$ technology that consists of a hard polymer matrix tablet that is difficult to manipulate. ${ }^{32}$ Clinical studies have demonstrated that the formulation was associated with significantly reduced scores for both drug liking and desire to take the drug again compared with a non-ADF of ER morphine after both oral ingestion and insufflation (after manipulation). ${ }^{33,34}$ Arymo ER has physical and chemical properties expected to make abuse by injection difficult.

\section{Agonist/antagonist combinations (currently marketed)}

Embeda $^{\circledR}$ (morphine sulfate and naltrexone HCl ER; Pfizer, Inc., New York, NY, USA), approved in 2014, comprises pellets of morphine sulfate, each containing a core of sequestered naltrexone that is intended to remain sequestered when the product is taken as prescribed. ${ }^{35}$ Naltrexone is released and exerts opioid antagonism if the tablet is crushed, potentially causing symptoms of withdrawal. ${ }^{35}$ Studies have indicated that the quantity of naltrexone released on manipulation is sufficient to attenuate the desired subjective effects of morphine following oral, ${ }^{36-38}$ intranasal, ${ }^{39}$ or $\mathrm{IV}^{40}$ administration of Embeda. Embeda has properties that are expected to reduce abuse via the oral and intranasal routes.

\section{Other ADF-labeled opioids (not currently marketed)}

Vantrela $^{\mathrm{TM}}$ ER (hydrocodone bitartrate ER; Teva Pharmaceuticals, North Wales, PA, USA), approved in 2017, uses OraGuard TM/CIMA technology, consisting of a polymer/ opioid-mixed core surrounded by two additional layers of polymers. ${ }^{41,42}$ This formulation resists isolation of the active ingredient through crushing, breaking, and dissolution, and retains some ER properties despite manipulation. Vantrela ER is expected to reduce IV abuse, and abuse via the oral and intranasal routes. ${ }^{42}$ 
Targiniq $^{\text {TM }}$ ER (oxycodone $\mathrm{HCl}$ and naloxone $\mathrm{HCl}$ ER; Purdue Pharma), approved in 2014, is an ER tablet containing oxycodone combined with naloxone - an antagonist that blocks the euphoric effects of oxycodone if the tablet is crushed or manipulated for snorting or IV injection. ${ }^{43}$ Targiniq ER has pharmacologic properties that are expected to reduce abuse via the intranasal and IV routes of administrations.

Troxyca ${ }^{\circledR}$ ER (oxycodone $\mathrm{HCl}$ and naltrexone ER; Pfizer, Inc., New York, NY, USA), approved in 2016, consists of a capsule filled with ER pellets of oxycodone with a sequestered core of naltrexone, an antagonist that blocks the euphoric effects of oxycodone if the pellets are crushed or manipulated for snorting or before swallowing. ${ }^{44}$ Troxyca ER has properties that are expected to reduce abuse via the oral and intranasal routes.

RoxyBond $^{\mathrm{TM}}$ (IR oxycodone; Daiichi Sankyo, Inc., Basking Ridge, NJ, USA) is the first and only IR opioid with FDA approval (2017) for its abuse-deterrent properties ${ }^{45}$ RoxyBond is formulated with proprietary technology (SentryBond) that makes the tablets difficult to manipulate for misuse and abuse, even when subjected to physical manipulation or attempts to chemically extract the opioid. ${ }^{45}$ In an abuse-potential study, intranasal administration of crushed RoxyBond was associated with significant reductions in drug liking and willingness to take the drug again scores when compared with crushed intranasal oxycodone IR tablets and intact oral RoxyBond ${ }^{45}$ Similar reductions in drug liking and desire to take the drug again scores were reported for crushed intranasal RoxyBond relative to intact oral RoxyBond. RoxyBond has physicochemical properties expected to make abuse via injection difficult and is expected to reduce abuse by the intranasal route of administration. RoxyBond is not yet commercially available.

\section{Other ADF strategies}

One strategy of abuse deterrence incorporates aversion properties into a formulation; components are added to the opioid formulation that produces an unpleasant effect if manipulated (eg, mucous membrane irritant for intranasal abuse). ${ }^{46}$ The unique delivery system strategy uses long-acting injectable or depot formulations that are difficult to manipulate. ${ }^{46}$ The use of a prodrug as an opioid ADF would require a chemical or enzymatic conversion to active drug. ${ }^{46}$ Currently, there are no approved drugs with these types of abuse-deterrent properties, although there are some in development (eg, Aversion ${ }^{\circledR}$; Acura, Palatine, IL, USA; BIOMD ${ }^{\mathrm{TM}}$; Ensysce Bioscience, San Diego, CA, USA).

\section{Abuse-deterrent opioids: post- marketing analyses}

A growing body of evidence suggests that reformulated (abuse-deterrent) OxyContin has decreased rates of abuse and diversion. ${ }^{22,47-49}$ However, some opioid ADFs are not yet commercially available, and others have not been on the market long enough to undergo post-marketing data analyses. Furthermore, access to ADFs may be limited by inadequate insurance coverage, especially with the lower cost of non-ADFs that remain in the marketplace. Some states have enacted laws to expand access to ADF opioids, but access remains challenging. As more abuse-deterrent opioid analgesic formulations become available, the societal cost savings associated with reductions in abuse may increase.${ }^{13}$ Further post-marketing studies will help evaluate if the availability of multiple ADFs will have an impact on abuse rates.

\section{Clinical/appropriate use of ADFs}

The FDA-approved indication for all ER opioid ADFs is for the management of pain severe enough to require daily, around-the-clock, long-term opioid treatment and for which alternative treatment options are inadequate. The only IR opioid with FDA-approved ADF claims (RoxyBond [oxycodone]) is indicated for the management of pain severe enough to require an opioid analgesic and for which alternative treatments are inadequate. ${ }^{45}$

As demonstrated by results from the clinical abusepotential studies discussed earlier, opioid ADFs appear much less appealing to opioid abusers by specific routes of abuse than are opioid non-ADFs. When considering pain management, it is also important to consider the patient's risk for opioid misuse or abuse as well as the potential risk for diversion (either unintentional or intentional). Therefore, opioid ADFs are expected to be an important component of a health care provider's comprehensive opioid risk management plan, along with the use of PDMPs, clinical assessment tools, toxicology testing, and co-prescribing of naloxone, among others.

\section{Integrating ADFs into practice}

Given the magnitude of the opioid crisis, it has been suggested that a "universal-precaution" approach to opioid prescribing should be followed, including abuse risk assessments and abuse-deterrence strategies for all patients receiving opioids. ${ }^{50}$ For any given patient, an initial determination must be made regarding the clinical appropriateness of an opioid for pain management (Box 1). Clinical practice guidelines 
Box I Best practices when prescribing abuse-deterrent formulations of opioids

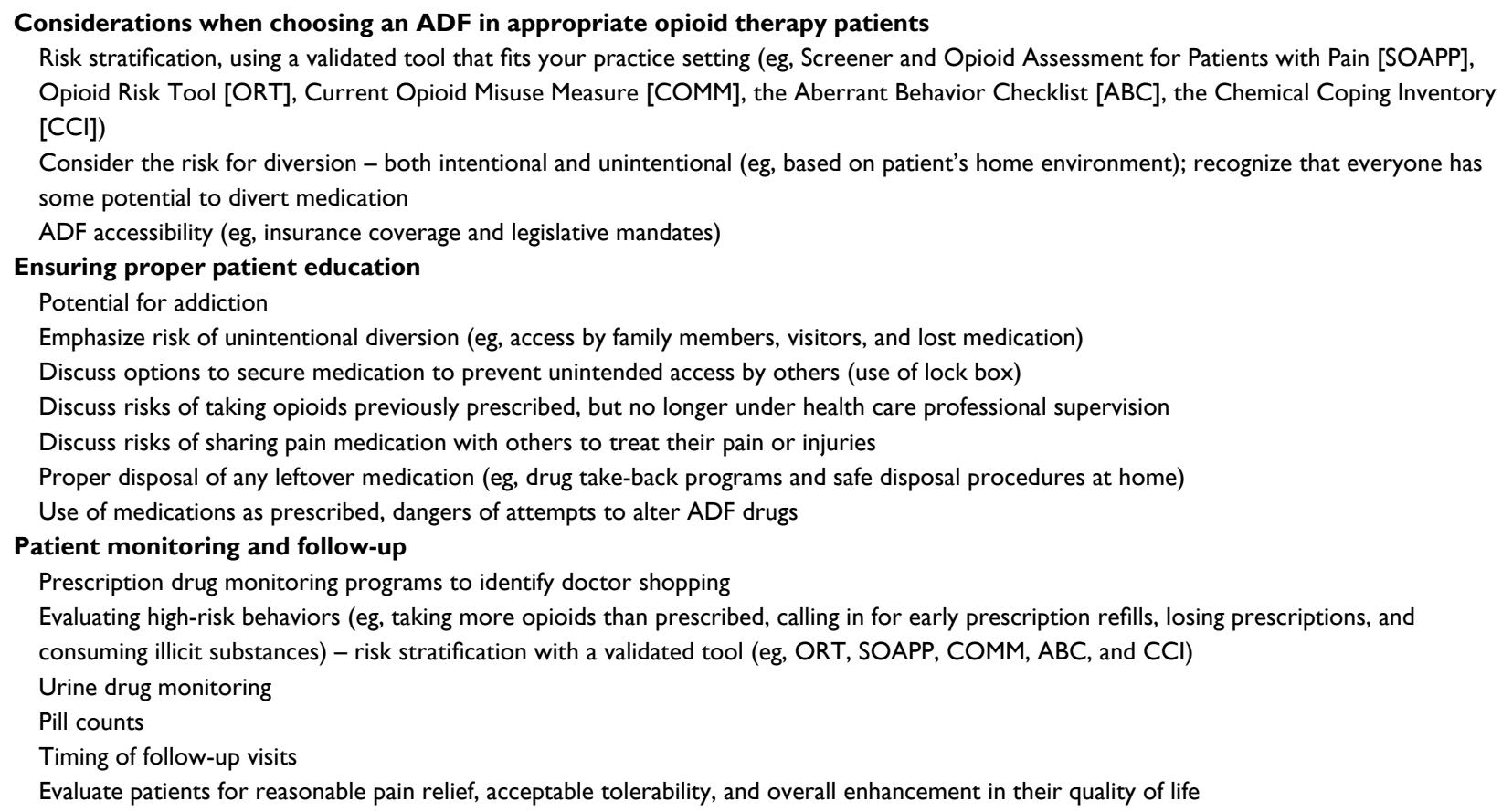

Abbreviation: ADF, abuse-deterrent formulations.

are available to aid in determining the appropriateness of opioid therapy. ${ }^{51-53}$

An important aspect of this process is the determination of an individual patient's potential for developing a substance use disorder. ${ }^{52}$ Adequate risk stratification requires performing a thorough physical examination and obtaining a complete patient history, including an assessment of psychosocial factors and family history. ${ }^{52}$ The use of a validated risk evaluation tool may be helpful in this endeavor, though it should be noted that the evidence is mixed regarding the accuracy and reliability of these instruments to predict the potential for substance abuse. ${ }^{51}$ Formal screening tools include the Screener and Opioid Assessment for Patients with Pain-Revised (SOAPP-R); Opioid Risk Tool (ORT); Current Opioid Misuse Measure (COMM); the Addiction Behavior Checklist (ABC); the Chemical Coping Inventory (CCI); and the Diagnosis, Intractability, Risk, Efficacy (DIRE) instrument. ${ }^{53,54}$

Urine drug monitoring can also be considered to establish a baseline measure of risk and monitor adherence during opioid therapy for chronic pain management. ${ }^{51}$ Urine screening is capable of detecting a majority of drugs for 1-3 days after exposure. ${ }^{54}$ PDMPs are another useful tool in making the determination regarding the clinical appropriateness of an opioid for a given patient. PDMPs are state-maintained electronic databases of controlled substance prescriptions that allow prescribers to view a patient's opioid prescription history to detect doctor- or pharmacy-shopping behaviors and identify patients who have received unusually high dosages or amounts of controlled substances. Some states collaborate and share PDMP information to expand the databases. It should be noted that in the NSDUH 2016 survey, only $1.4 \%$ of opioid misusers obtained their source of opioids through more than one doctor. ${ }^{6}$

Even if a patient is at extremely low risk for developing a substance use disorder, it is important to recognize the potential risk for diversion within his or her environment. For example, a patient may share his or her pain medication with another person to treat that individual's pain. Alternatively, if the medication is not secured, it may be taken by others in the household (either for their own consumption or for illegal distribution) without the patient's knowledge, or medication can be stolen by visitors to the household (acquaintances, caregivers, service providers [eg, electrician and maid service]). ${ }^{9,55-57}$ As mentioned earlier, approximately $53 \%$ of respondents in a national survey on drug use and health indicated that the source of their prescription opioid for their most recent abuse or misuse experience was family or friends. ${ }^{6}$

Patient education on the risks of abuse and diversion is vital, particularly given the inherent risk of unintentional diversion. A handout like that shown in Figure 4 could be a useful tool to help explain to patients the risks of diversion. Safe storage of opioid medications in a locked box or 
Keeping friends and family safe from prescription drug abuse

The risks associated with taking prescription medication inappropriately include addiction, overdose, and death. It is important that you take your medication as prescribed and prevent it from being used by someone other than yourself (or prevent the use of the medication by someone other than who received the prescription). Below are some guidelines for the proper use and care of prescription medication:

- Keep out of reach of children

- Do not leave prescription medication easily accessible

- If you are concerned that someone may be taking your pills (eg, fewer pills in bottle than expected), lock up your medication

- If it is difficult for you to remember to take your medication properly, use a pill organizer

- Do not give prescription medication to anyone else, even if they have similar symptoms or if they ask for some

- Do not use old medication for new needs

- If you have pills left over after you no longer need them, dispose of them properly (do not keep them for future use)

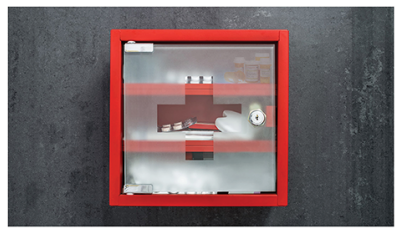

Figure 4 Example handout for patients to help reduce diversion risks.

cabinet should be emphasized, highlighting the importance of keeping opioid medications secure from unintended users. ${ }^{9}$ Patients should also be made aware of safe disposal and drug take-back options in the community for disposal of unused medications. ${ }^{18,58}$ The health care provider should reinforce that prescribed opioids are only to be taken for the condition being treated under the supervision of a health care professional and that it is inappropriate to retain unused pills for self-management of pain for future conditions. Patients should also be counseled on the safe and appropriate use of the medication, the consequences of not taking it as directed, the adverse consequences of long-term opioid therapy, and the potential for addiction. ${ }^{51}$ It is also important to assess and mitigate barriers to patients' accessibility of ADFs such as cost due to lack of insurance and pharmacy benefit formulary restrictions. Several states have introduced legislation mandating that $\mathrm{ADF}$ opioids be available on formularies and requiring insurance coverage of $\mathrm{ADFs} .{ }^{59}$

Ongoing monitoring of patients receiving opioids to ensure appropriate use and effectiveness (in terms of pain severity and functional ability) is critical. Validated screening tools, PDMPs, and urine drug testing as described earlier can be used, along with an evaluation of the " $4 \mathrm{As"}$ (analgesia, activities of daily living, adverse events, aberrant behavior). ${ }^{51,54}$ The challenge is to balance a patient's pain relief, potentially harmful consequences of opioids, and quality of life. Under prescribing may lead to poorly managed pain while overprescribing can lead to patient lethargy, his or her inability to perform daily functions, and other potentially harmful consequences, including death.

\section{Conclusion}

Balancing the appropriate medical use of prescription opioids for the treatment of moderate-to-severe acute and chronic pain with legitimate concerns about misuse, abuse, and diversion is an ongoing challenge for health care providers, particularly because many individuals who misuse prescription opioids obtain them without a prescription, often from friends or relatives. ${ }^{6}$ This is compounded by a lack of prescriber training on key issues such as recognizing drug diversion, addiction, and signs of abuse. ${ }^{54,60}$ ADFs are one component of a comprehensive opioid risk management strategy that requires the cooperation of all stakeholders. Physician assistants (PAs) and nurse practitioners (NPs) are on the front lines in providing necessary pain care while simultaneously battling opioid misuse. PAs and NPs hold a key role in recognizing the risks inherent in the diversion (intentional and unintentional) of prescription opioids into the community, identifying patients at risk for abuse, and mitigating the risks of misuse by the patient.

\section{Acknowledgments}

Medical writing support was provided by Angela Cimmino, PharmD, and Kelly M Cameron, PhD, ISMPP CMPP, of JB Ashtin (funded by Daiichi Sankyo, Inc., USA). Daiichi Sankyo had the opportunity to review the manuscript draft for factual accuracy.

\section{Author contributions}

The authors, JAA and TMS, were involved in the concept/ design of the manuscript, the interpretation of the literature when developing the manuscript, as well as the critical review and final approval of the manuscript for submission.

\section{Disclosure}

JAA received honorarium for speakers' bureau or consulting from AstraZeneca, Collegium, Daiichi Sankyo, Depomed, Millennium Labs, Pernix, St Jude Medical Neuromodulation Systems, Egalet, and Quest Diagnostics.

TMS received honorarium for consulting from Allergan, Daiichi Sankyo, DepoMed, Pernix, Purdue Pharma, and Shionogi.

The authors report no other conflicts of interest in this work. 


\section{References}

1. Paulozzi LJ. Vital signs: overdoses of prescription opioid pain relievers - United States, 1999-2008. MMWR Morb Mortal Wkly Rep. 2011;60:1487-1492.

2. National Institute on Drug Abuse. Overdose death rates 2017. Available from: https://www.drugabuse.gov/related-topics/trends-statistics/ overdose-death-rates. Accessed February 6, 2018.

3. Centers for Disease Control and Prevention, National Center for Health Statistics. Multiple Cause of Death 1999-2016 on CDC WONDER Online Database, released December, 2017. Data are from the Multiple Cause of Death Files, 1999-2016, as compiled from data provided by the 57 vital statistics jurisdictions through the Vital Statistics Cooperative Program. Accessed from: https://wonder.cdc.gov/controller/saved/ D77/D38F188. Accessed April 13, 2018.

4. Ahmad FB, Rossen LM, Spencer MR, et al. Provisional drug overdose death counts. National Center for Health Statistics. 2018. Available from: https://www.cdc.gov/nchs/nvss/vsrr/drug-overdose-data.htm. Accessed February 19, 2018.

5. Smith SM, Dart RC, Katz NP, et al. Classification and definition of misuse, abuse, and related events in clinical trials: ACTTION systematic review and recommendations. Pain. 2013;154:2287-2296.

6. Key substance use and mental health indicators in the United States: Results from the 2016 National Survey on Drug Use and Health (HHS Publication No. SMA 17-5044, NSDUH Series H-52). Rockville, MD. 2017. Available from: https://store.samhsa.gov/shin/content//SMA175044/SMA17-5044.pdf. Accessed December 7, 2017.

7. Florence CS, Zhou C, Luo F, et al. The economic burden of prescription opioid overdose, abuse, and dependence in the United States, 2013. Med. Care. 2016;54:901-906.

8. Hall AJ LJ, Toblin RL, Kaplan JA, et al. Patterns of abuse among unintentional pharmaceutical overdose fatalities. J Am Med Assoc. 2008;300:2613-2620.

9. Binswanger IA, Glanz JM. Pharmaceutical opioids in the home and youth: implications for adult medical practice. Subst Abus. 2015;36:141-143.

10. Blackhall LJ, Alfson ED, Barclay JS. Screening for substance abuse and diversion in Virginia hospices. J Palliat Med. 2013;16:237-242.

11. Alexander L, Weingarten B. A pharmacist's guide to the emerging abuse deterrence technology used in opioid analgesics. Pharmacy Times. 2014;August:1-4.

12. Paulozzi LJ. Senate Health Committee: trends in unintentional drug overdose deaths 2008. Available from: https://www.judiciary.senate. gov/imo/media/doc/paulozzi_testimony_03_12_08.pdf. Accessed January 5, 2018.

13. Gasior M, Bond M, Malamut R. Routes of abuse of prescription opioid analgesics: a review and assessment of the potential impact of abusedeterrent formulations. Postgrad Med. 2016;128:85-96.

14. Green JL, Bucher Bartelson B, Le Lait MC, et al. Medical outcomes associated with prescription opioid abuse via oral and non-oral routes of administration. Drug Alcohol Depend. 2017;175:140-145.

15. Budman SH, Grimes Serrano JM, Butler SF. Can abuse deterrent formulations make a difference? Expectation and speculation. Harm Reduct J. 2009;6:8.

16. Lankenau SE, Teti M, Silva K, et al. Initiation into prescription opioid misuse amongst young injection drug users. Int J Drug Policy. 2012;23:37-44.

17. Yewell J, Haydon R, Archer S, et al. Complications of intranasal prescription narcotic abuse. Ann Otol Rhinol Laryngol. 2002;111:174-177.

18. U.S. Department of Health and Human Services, Food and Drug Administration, Center for Drug Evaluation and Research. Abuse-deterrent opioids - evaluation and labeling: guidance for industry. Silver Spring, MD: U.S. Department of Health and Human Services; 2015. Available from: https://www.fda.gov/downloads/Drugs/Guidances/UCM334743. pdf. Accessed December 7, 2017.

19. OxyContin ${ }^{\circledR}$ (oxycodone hydrocodone) extended-release [package insert]. Stamford, CT: Purdue Pharma, L.P.; 2015.
20. Hale ME, Moe D, Bond M, et al. Abuse-deterrent formulations of prescription opioid analgesics in the management of chronic noncancer pain. Pain Manag. 2016;6:497-508.

21. Harris SC, Perrino PJ, Smith I, et al. Abuse potential, pharmacokinetics, pharmacodynamics, and safety of intranasally administered crushed oxycodone $\mathrm{HCl}$ abuse-deterrent controlled-release tablets in recreational opioid users. J Clin Pharmacol. 2014;54:468-477.

22. Dart RC, Surratt HL, Cicero TJ, et al. Trends in opioid analgesic abuse and mortality in the United States. N Engl J Med. 2015;372:241-248.

23. Sellers EM, Perrino PJ, Colucci SV, et al. Attractiveness of reformulated OxyContin ${ }^{\circledR}$ tablets: assessing comparative preferences and tampering potential. J Psychopharmacol. 2013;27:808-816.

24. Hysingla ${ }^{\mathrm{TM}}$ ER (hydrocodone bitartrate) extended-release tablets [package insert]. Stamford, CT: Purdue Pharma L.P.; 2014.

25. Harris SC, Cipriano A, Colucci SV, et al. Oral abuse potential, pharmacokinetics, and safety of once-daily, single-entity, extendedrelease hydrocodone (HYD) in recreational opioid users. Pain Med. 2017;18:1278-1291.

26. Harris SC, Cipriano A, Colucci SV, et al. Intranasal abuse potential, pharmacokinetics, and safety of once-daily, single-entity, extendedrelease hydrocodone (HYD) in recreational opioid users. Pain Med. 2016;17:820-831.

27. MorphaBond ${ }^{\mathrm{TM}}$ ER (morphine sulfate) extended-release tablets [package insert]. Basking Ridge, NJ: Daiichi Sankyo, Inc.; 2017.

28. Webster LR, Pantaleon C, Shah MS, et al. A randomized, double-blind, double-dummy, placebo-controlled, intranasal drug liking study on a novel abuse-deterrent formulation of morphine-morphine ARER. Pain Med. 2017;18:1303-1313.

29. Xtampza ${ }^{\circledR}$ ER (oxycodone) extended-release capsules [package insert]. Canton, MA: Collegium Pharmaceutical, Inc.; 2016.

30. Kopecky EA, Fleming AB, Levy-Cooperman N, et al. Oral human abuse potential of oxycodone DETERx ${ }^{\circledR}$ (Xtampza ${ }^{\circledR}$ ER). J Clin Pharmacol. 2017;57:500-512.

31. Webster LR, Kopecky EA, Smith MD, et al. A randomized, double-blind, double-dummy study to evaluate the intranasal human abuse potential and pharmacokinetics of a novel extended-release abuse-deterrent formulation of oxycodone. Pain Med. 2016;17:1112-1130.

32. Arymo ${ }^{\mathrm{TM}}$ ER (morphine sulfate) extended-release tablets [package insert]. Wayne, PA: Egalet Corporation; 2017.

33. Smith MD, Webster LR, Lawler J, et al. Human abuse potential of an abuse-deterrent (AD), extended-release (ER) morphine product candidate (morphine-ADER injection-molded tablets) versus extendedrelease morphine administered orally in nondependent recreational opioid users. Pain Med. 2017;18:898-907.

34. Webster LR, Smith MD, Lawler J, et al. Human abuse potential of an abuse-deterrent (AD), extended-release (ER) morphine product candidate (morphine-ADER injection-molded tablets) vs extended-release morphine administered intranasally in nondependent recreational opioid users. Pain Med. 2017;18:1695-1705.

35. Embeda ${ }^{\circledR}$ (morphine sulfate and naltrexone hydrochloride) extendedrelease capsules [package insert]. New York, NY: Pfizer Inc.; 2014.

36. Setnik B, Roland CL, Goli V, et al. A clinical trial to determine if corelease of morphine and naltrexone from crushed extended-release capsules induces withdrawal in opioid-dependent patients: a descriptive analysis of six patients. J Opioid Manag. 2013;9:139-150.

37. Setnik B, Sommerville K, Goli V, et al. Assessment of pharmacodynamic effects following oral administration of crushed morphine sulfate and naltrexone hydrochloride extended-release capsules compared with crushed morphine sulfate controlled-release tablets and placebo in nondependent recreational opioid users. Pain Med. 2013;14: 1173-1186.

38. Stauffer J, Setnik B, Sokolowska M, et al. Subjective effects and safety of whole and tampered morphine sulfate and naltrexone hydrochloride (ALO-01) extended-release capsules versus morphine solution and placebo in experienced non-dependent opioid users: a randomized, double-blind, placebo-controlled, crossover study. Clin Drug Investig. 2009;29:777-790. 
39. Setnik B, Goli V, Levy-Cooperman N, et al. Assessing the subjective and physiological effects of intranasally administered crushed extended-release morphine formulations with and without a sequestered naltrexone core in recreational opioid users. Pain Res Manag. 2013;18:e55-e62.

40. Webster LR, Johnson FK, Stauffer J, et al. Impact of intravenous naltrexone on intravenous morphine-induced high, drug liking, and euphoric effects in experienced, nondependent male opioid users. Drugs $R D$. 2011;11:259-275.

41. Farber R, Rae S. This week in FDA vs. Biotech Part I, Will Teva's Vantrela get abuse-deterrent label? Market Exclusive: Weekly Biotech Report 2016. Available from: https://marketexclusive.com/ weekly-biotech-report-covering-vantrela/2016/06/. Accessed June 26, 2017.

42. Vantrela ${ }^{\mathrm{TM}}$ ER package insert (hydrocodone bitartrate) extended-release tablets [package insert]. North Wales, PA: Teva Pharmaceuticals; 2017.

43. Targiniq ${ }^{\mathrm{TM}}$ ER (oxycodone hydrochloride and naloxone hydrochloride) extended-release tablets [package insert]. Stamford, CT: Purdue Pharma L.P; 2016.

44. Troxyca ${ }^{\circledR}$ ER (oxycodone hydrochloride and naltrexone hydrochloride) extended-release capsules [package insert]. New York, NY: Pfizer, Inc; 2016.

45. RoxyBond ${ }^{\mathrm{TM}}$ (oxycodone hydrochloride) tablets [package insert]. Morristown, NJ: Inspirion Delivery Sciences, LLC; 2017.

46. Webster LR, Markman J, Cone EJ, et al. Current and future development of extended-release, abuse-deterrent opioid formulations in the United States. Postgrad Med. 2017;129:102-110.

47. Chilcoat HD, Coplan PM, Harikrishnan V, et al. Decreased diversion by doctor-shopping for a reformulated extended release oxycodone product (OxyContin). Drug Alcohol Depend. 2016;165:221-228.

48. Coplan PM, Kale H, Sandstrom L, et al. Changes in oxycodone and heroin exposures in the National Poison Data System after introduction of extended-release oxycodone with abuse-deterrent characteristics. Pharmacoepidemiol Drug Saf. 2013;22:1274-1282.
49. Severtson SG, Ellis MS, Kurtz SP, et al. Sustained reduction of diversion and abuse after introduction of an abuse deterrent formulation of extended release oxycodone. Drug Alcohol Depend. 2016;168:219-229.

50. Radnovich R, Chapman CR, Gudin JA, et al. Acute pain: effective management requires comprehensive assessment. Postgrad Med. 2014;126:59-72.

51. Manchikanti L, Kaye AM, Knezevic NN, et al. Responsible, safe, and effective prescription of opioids for chronic non-cancer pain: American Society of Interventional Pain Physicians (ASIPP) Guidelines. Pain Physician. 2017;20:S3-S92.

52. Chou R, Fanciullo GJ, Fine PG, et al. Clinical guidelines for the use of chronic opioid therapy in chronic noncancer pain. J Pain. 2009; 10:113-130.

53. Dowell D, Haegerich TM, Chou R. CDC Guideline for prescribing opioids for chronic pain - United States, 2016. MMWR Recomm Rep. 2016;65:1-49.

54. Kaye AD, Jones MR, Kaye AM, et al. Prescription opioid abuse in chronic pain: an updated review of opioid abuse predictors and strategies to curb opioid abuse (Part 2). Pain Physician. 2017;20:S111-S133.

55. Pancari J, Baird C. Managing prescription drug diversion risks: caring for individuals at home. J Addict Nurs. 2014;25:114-121.

56. Setnik B, Roland CL, Goli V, et al. Self-reports of prescription opioid abuse and diversion among recreational opioid users in a Canadian and a United States city. J Opioid Manag. 2015;11:463-473.

57. Lewis ET, Cucciare MA, Trafton JA. What do patients do with unused opioid medications? Clin J Pain. 2014;30:654-662.

58. Yanovitzky I. A multiyear assessment of public response to a statewide drug take-back and disposal campaign, 2010 to 2012. Health Educ Behav. 2017;44:590-597.

59. Institute for Clinical and Economic Review. Abuse-deterrent opioids: final evidence report 2017. Available from: https://icer-review.org/ material/adf-final-report/. Accessed November 27, 2017.

60. Tetrault J, JL B. Non-medical prescription opioid use and prescription opioid use disorder: a review. Yale J Biol Med. 2015;88:227-233.
Journal of Multidisciplinary Healthcare

\section{Publish your work in this journal}

The Journal of Multidisciplinary Healthcare is an international, peerreviewed open-access journal that aims to represent and publish research in healthcare areas delivered by practitioners of different disciplines. This includes studies and reviews conducted by multidisciplinary teams as well as research which evaluates the results or conduct of such teams or health

\section{Dovepress}

care processes in general. The journal covers a very wide range of areas and welcomes submissions from practitioners at all levels, from all over the world. The manuscript management system is completely online and includes a very quick and fair peer-review system. Visit http://www.dovepress.com/ testimonials.php to read real quotes from published authors. 